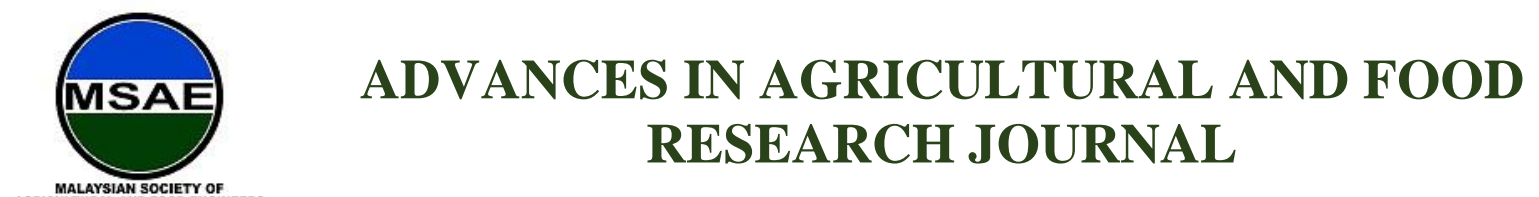

HH PUBLISHER

Original Research Article

\title{
Performance Comparison of Experimental IoT Based Drip and Fibrous Capillary Irrigation Systems in The Cultivation of Cantaloupe Plants
}

\begin{abstract}
Abioye Abiodun Emmanuel ${ }^{1,2}$, Mohammad Shukri Zainal Abidin ${ }^{1 *}$, Mohd Saiful Azimi Mahmud ${ }^{1}$, Salinda Buyamin ${ }^{1}$, Mohamad Hafis Izran Ishak ${ }^{1}$, Muhammad Khairie Idham Abd Rahman ${ }^{1}$, Umar Zangina $^{1}$

${ }^{1}$ Department of Control and Mechatronics Engineering, School of Electrical Engineering, Universiti Teknologi Malaysia (UTM) Skudai, Johor, Malaysia.

${ }^{2}$ Department of Electrical/Electronic Engineering, Akanu Ibiam Federal Polytechnic, Unwana, Ebonyi State, Nigeria.
*Corresponding author: Mohammad Shukri Zainal Abidin, Department of Control and Mechatronics Engineering, School of Electrical Engineering, Universiti Teknologi Malaysia (UTM) Skudai, Johor, Malaysia; shukri@utm.my

Abstract: The demand for freshwater and food is extremely high due to rapid growth in the world's population. the effect of global warming and climate change poses a severe threat on water use and food security. Conventional irrigation system affected due to inefficient management of water and energy, while the insufficient supply of water to plant increases their stress which often affects its growth and development. Hence, there is a need to increase research focus on water use efficiency in irrigated agriculture. This paper aims to investigate the performance of smart drip and subsurface fibrous capillary irrigation experiment for the cultivation of the cantaloupe plant to increase the yield and quality of fruit while decreasing the water and energy usage. An Internet of Things (IoT) approach was used to improve monitoring of soil, weather, plant and control of water application to achieve enhancement of subsurface fibrous capillary and drip irrigation system. The performance comparisons of both methods were evaluated in terms of water-saving in greenhouse cultivation experiment. The results showed that the smart fibrous capillary irrigation has water productivity index (WPI) of $19 \mathrm{~kg} / \mathrm{m} 3$ with an average fruit sweetness of 13.5 Brix. While drip irrigation has WPI of $4.85 \mathrm{~kg} / \mathrm{m} 3$ and average sweetness of 10 Brix on the harvested fruit after 90 days of cantaloupe plant cultivation experiment. These have shown that precision irrigation through enhanced smart fibrous capillary irrigation can be used to achieve high water-saving and a good quality yield. It is expected that the research output will help to improve water-saving agriculture towards achieving food security.

Keywords: Water saving; capillary irrigation; drip irrigation; internet of things; water use efficiency

Received: $14^{\text {th }}$ September 2020

Citation: Abioye AE, Zainal Abidin MS, Azimi Mahmud MS, et al. Performance comparison of experimental IoT based drip and fibrous capillary irrigation systems in the cultivation of cantaloupe

Accepted: $14^{\text {th }}$ October 2020 plants. Adv Agri Food Res J 2020; 1(2): a0000121.

Available Online: $6^{\text {th }}$ November 2020 https://doi.org/10.36877/aafrj. a0000121 


\section{Introduction}

As the population grows, urbanization rates and effect of climate change in Asia rise rapidly, stress on the region's water resources is intensifying with an adverse effect on food production, hence the need for increased focus on precision agriculture (Prokurat, 2015; Asia Society, 2019). Precision in agriculture plays an important role in maintaining food security with least labours and energy. At the same time, improving environmental management to ensure improvement in food production efforts and meet up with the increased consumption demand (Saiful et al., 2020). Also, towards achieving food security, proper management of irrigation water using different irrigation techniques such as capillary and drip irrigation system for cultivation of various crops is very important (Oborkhale et al., 2015).

Cantaloupe plant is one of the highly valued tropical fruit in Malaysia which form part of a healthy diet with refreshing characteristics. According to Masde and Mohd (2016), achieving fruit quality and yield of cantaloupe plant has become a major issue among farmers and consumers, which largely depends on the water management during the cultivation of cantaloupe plant. This calls for the adoption of smart irrigation technology through the use of Internet of Things (IoT) into the advancement of the different methods of irrigation system commonly used for its cultivation (Rahman et al., 2019).

A drip system is one of the methods commonly used for irrigation of cantaloupe fruits. It consists of a network of water pipes with emitters laid on the soil surface through which water is applied towards the root of the plant (Abioye et al., 2020). The shortcomings of this method of irrigation system include increased rate of water loss, high cost of the installation, emitters clogging and breakage problems due to the intrusion of roots or the suction of solid particles from the soil matrix, and the difficulty of detecting and repairing potential leakage problems (Martínez \& Reca, 2014).

The deficiency of this method needs to be addressed. Subsurface capillary irrigation has the potential of achieving precision irrigation and improves water use efficiency as reported by Li et al., (2018), Zainal Abidin et al., (2014) and Idham et al., (2018). Capillary irrigation is a subsurface type of irrigation, where water is transported from the water source directly to the root zone of the plant using different capillary media such as fibrous, wicks, mat and flow system (Semananda et al., 2018). The advancement of this method will allow precise individual crop water characteristics and new strategies for efficient management of irrigation supply (Zainal Abidin et al., 2014).

Previous research works on the effects of drip irrigation and plastic mulch on cantaloupe plants yield as reported by Seyfi and Rashidi (2007), shows that the combination of both techniques has improved the efficiency of water usage and yield in terms of weight and thickness of the fruit. Similarly, Martínez and Reca (2014) compared the efficiency of water use of surface drip irrigation to subsurface drip irrigation based on three years experiment on an olive orchard. The result shows that the subsurface drip irrigation system performs better than the surface drip system in terms of water-saving and crop yield. 
Rhuanito et al., (2016) proposed a control system for water stress management using circulating aquaponics system for the cantaloupe fruit quality and yield rate. Also, Wiangsamut and Makhonpas (2017) demonstrated the performance of four (4) varieties of cantaloupe fruit which have been irrigated with a hydroponic system and drip irrigation system. The findings suggested that cantaloupe plant could best be cultivated with drip irrigation system rather than the hydroponic system, due to better fruitiness, weight and thickness.

Since little work have been reported on the performance comparison of drip and fibrous capillary irrigation on cantaloupe plant, this paper presents the investigation of drip and fibrous capillary irrigation system for cantaloupe plant cultivation based on yield, quality of the harvested fruit and water use efficiency. To evaluate the performance of both irrigation methods, field experiment has been performed under different irrigation schemes in greenhouse cultivated of cantaloupe plants.

\section{Literature Review}

\subsection{Experimental Design}

The cultivation experiment on cantaloupe plants was conducted in a greenhouse environment located in Universiti Teknologi Malaysia, Johor Bahru $\left(1.05633^{\circ} \mathrm{N}, 103.6382^{\circ}\right.$ E). A $0.15 \mathrm{~mm}$ UV plastic was used as the rooftop while a treated 24 mesh net was used to surround and cover up the greenhouse environment, to prevent an attack from pest while providing natural ventilation.

The experiment was carried out in two different greenhouses namely (GH1 and GH2) using coco peat inside the poly bags as a growing medium as shown in Figure 1(a) and (b). Inside GH1 with one treatment is the IoT based drip irrigation system with emitters placed closed to the roots zone of the plants were installed to supply water to the coco peat inside the poly bags. While inside $\mathrm{GH} 2$ is the set up for IoT based fibrous capillary with three different treatments, namely adaptive controlled with a horizontal capillary fibrous capillary interface, constant float sensor controlled with a horizontal fibrous capillary interface and lastly constant float sensor controlled with a vertical fibrous capillary interface (Rahman et al., 2019).

The coco peat inside the polybags was the growing medium used to minimise soil erosion, runoff and save water. The coco peat is a good growing medium with good water holding capacity as well as moderate electrical conductivity and $\mathrm{pH}$ which is suitable for greenhouse cultivation (Awang et al., 2009; Yahya et al., 1997). 


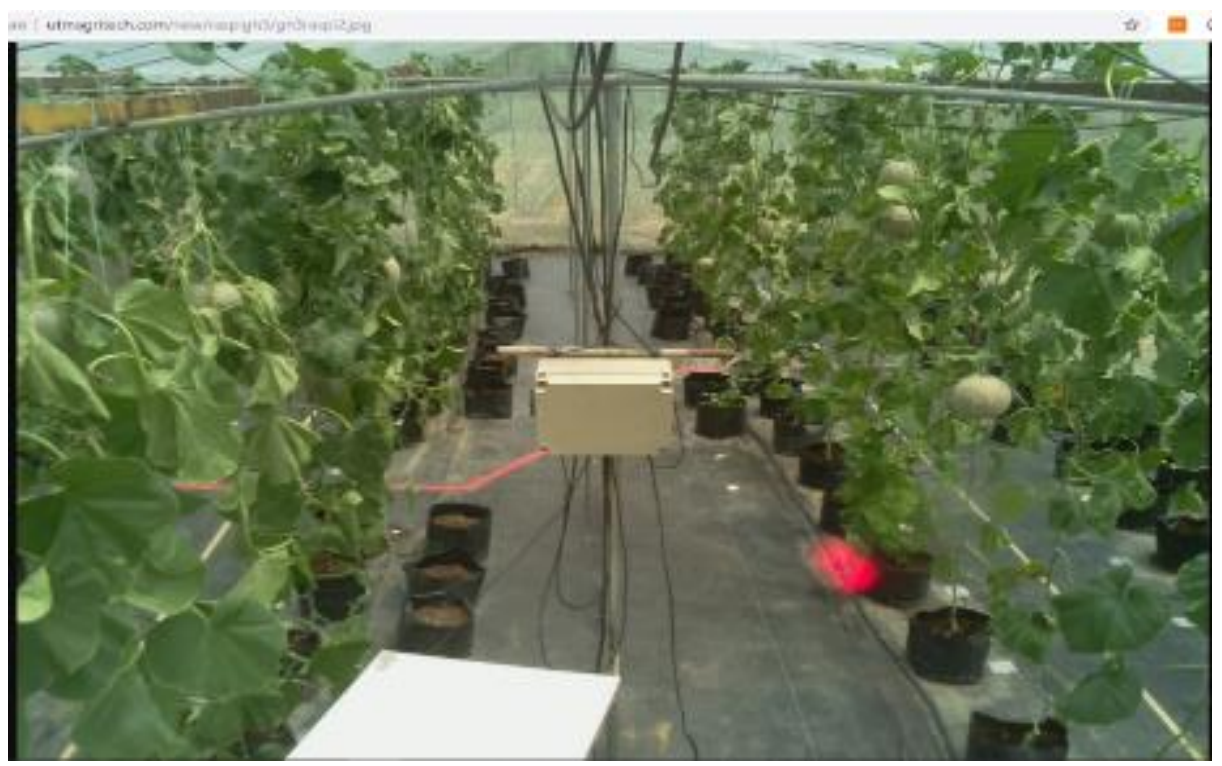

(a) Drip irrigation monitoring system in GH1

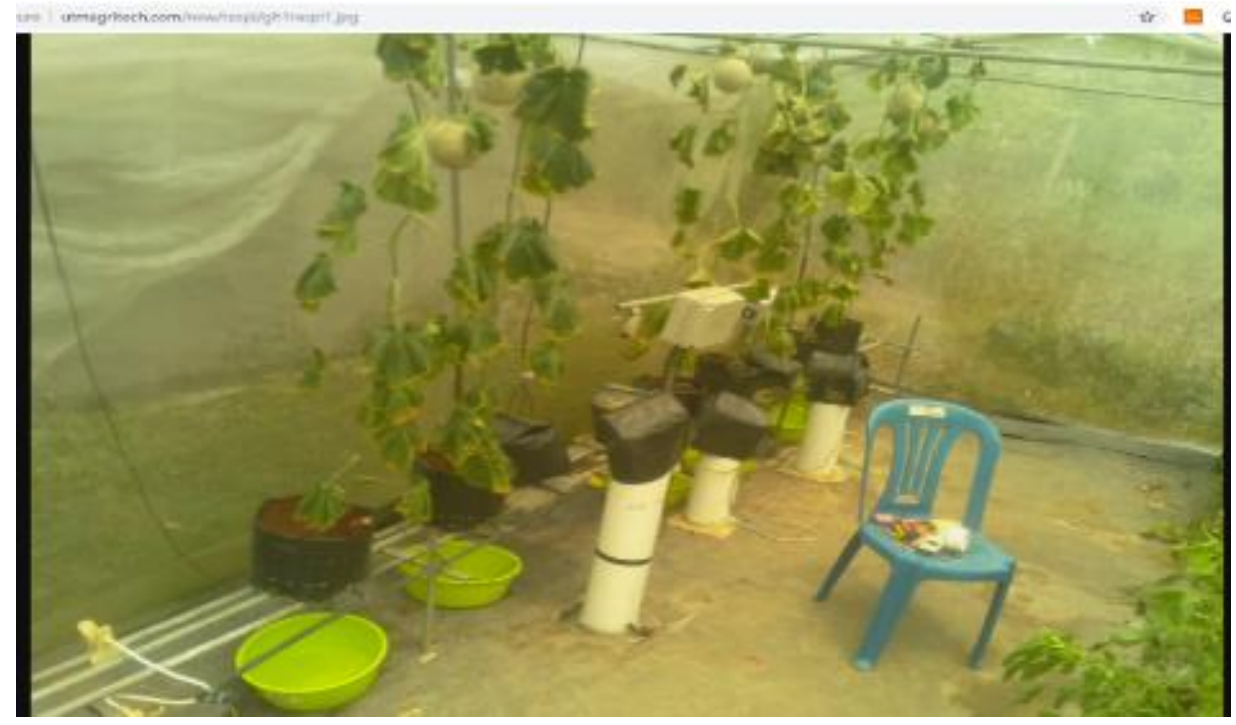

(b) Capillary irrigation monitoring system in $\mathrm{GH} 2$

Figure 1 (a) and (b). Visual monitoring of cantaloupe plant cultivation via raspberry pi camera at GH1 and $\mathrm{GH} 2$.

The experimental cultivation of the cantaloupe plants started with the planting of the seedling as a nursery on the $1^{\text {st }}$ of July 2019 , after which it germinated after four days and ready for transplanting on the $14^{\text {th }}$ of July 2019. Seventy-five (75) plants for drip irrigated, while six plants for capillary irrigation (two each for three treatments) were transplanted on 
the $1^{\text {st }}$ of August 2019 into the polybag within that greenhouse that is naturally ventilated. An EC value of $1 \mathrm{dS} / \mathrm{m}$, was maintained with $\mathrm{AB}$ liquid fertilizer, which was used to aid the growth for two weeks after transplant. A real-time monitoring of volumetric water content of the soil using a VH400 soil moisture sensor and estimated reference evapotranspiration via a weather station was used for optimal scheduling of both irrigation systems. The estimated reference evapotranspiration was used to determine the water loss, which is dependent on the crop coefficient at the different growth stage of the plant. The irrigation volume in terms of total water use (TWU) was measured using an IoT based flowmeter mounted on the main water supply pump of the greenhouse, which was used to compensate for the water loss was based on the actual evapotranspiration. Figure 1 (a) and (b) represent smart based drip and fibrous capillary irrigation with IoT monitoring system.

Real-time images of the cantaloupe plant are captured at every six hours with the help of the Crontab scheduling programming of the raspberry pi and its camera, during the day and uploaded to the IoT webpage where the plant performance in two greenhouses remotely was monitored (Abioye et al., 2020). With the help of these monitoring, we could easily know if the plant is stressed or wilt as well as growth performance. The performance comparison was further carried out using analysis of variance (ANOVA) to test the significant differences between the four treatments. The hypothesis was formulated as follows:

The null hypothesis Ho: There is no significant difference between the four treatments group that is mathematically: $\left(H_{O}=A=B=C=D\right)$.

The null hypothesis Ho: There is no significant difference between the four treatments group that is mathematically: $\left(H_{O}=A=B=C=D\right)$.

The degree of freedom for the total group $=n-1$

$$
=8-1=7
$$

Where $n$ is the number of samples

Degree of freedom for the treatment group $k-1$

$$
4-1=3
$$

Where $k$ is the number of treatments

The error for the degree of freedom $d f(e)=d(a)-d f$

The grand mean $Y_{i j}$

The total sum of square (ss) $=\sum\left(\left(Y_{i j}-\bar{Y} . .\right)^{2}\right)$

Treatment sum of square (ss) $=\sum\left(n_{i}\left(Y_{i j}-\bar{Y} . .\right)^{2}\right)$ 
Error for ss $=$ Total ss - Treatment ss

Mean Square for Treatment for Table $4\left(M S_{T}\right)=\frac{S S_{T}}{D F_{T}}=0.189$

Mean Square for Error for Table $4\left(M S_{E}\right)=\frac{S S_{E}}{D F_{E}}=0.01$

F Statistics $\left(F_{T}\right)=\frac{M S_{T}}{M S_{E}}$

\section{Result and Discussion}

The result of the performance evaluation is presented in Figure 2 to 5 and Tables 1 to 3. Different indices were used to determine the performance comparison of the two irrigation methods on the cultivated cantaloupe plants, which are cumulative plant height (m), measured leaf area $\left(\mathrm{cm}^{2}\right)$, cumulative water consumption (litre), water productivity index (WPI- $\mathrm{kg} / \mathrm{m}^{3}$ ), the weight of fruit $(\mathrm{kg})$ and sweetness of fruit (brix).

Since the number of poly bags for the drip irrigation system in GH1 is higher than the fibrous capillary in GH2, two samples of each treatment were picked for normalization and averaged to get each of the results for treatment A, B, C and D. Some of the harvested fruits can be seen in Figure 2.

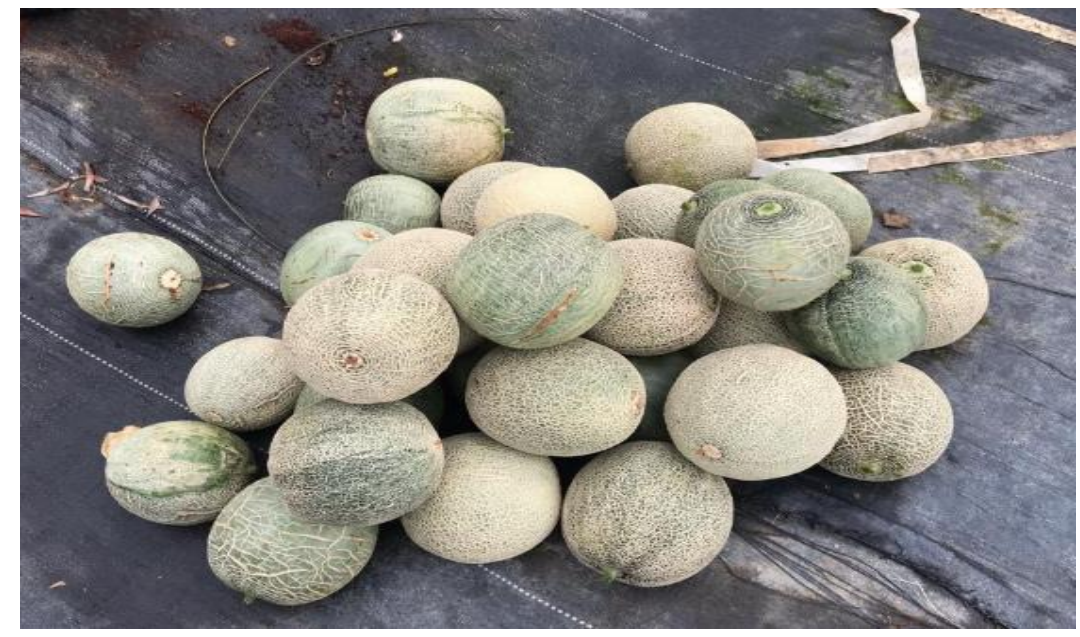

Figure 2. Harvested cantaloupe fruits.

Figure 3 illustrates a graph of cumulative water consumed during the period of cultivation of the plant, from which the drip-irrigated plant has the highest water consumed during the cultivation period. This could be due to the high rate of water loss experienced by the drip irrigation system because of evapotranspiration since water is applied to the root of the plant on the surface of the soil. From Figure 3, the drip irrigation (Treatment D) has the 
highest water consumption when compared to the three other treatments of fibrous capillary irrigation (Treatment A, B and C) per polybag after it was normalized.

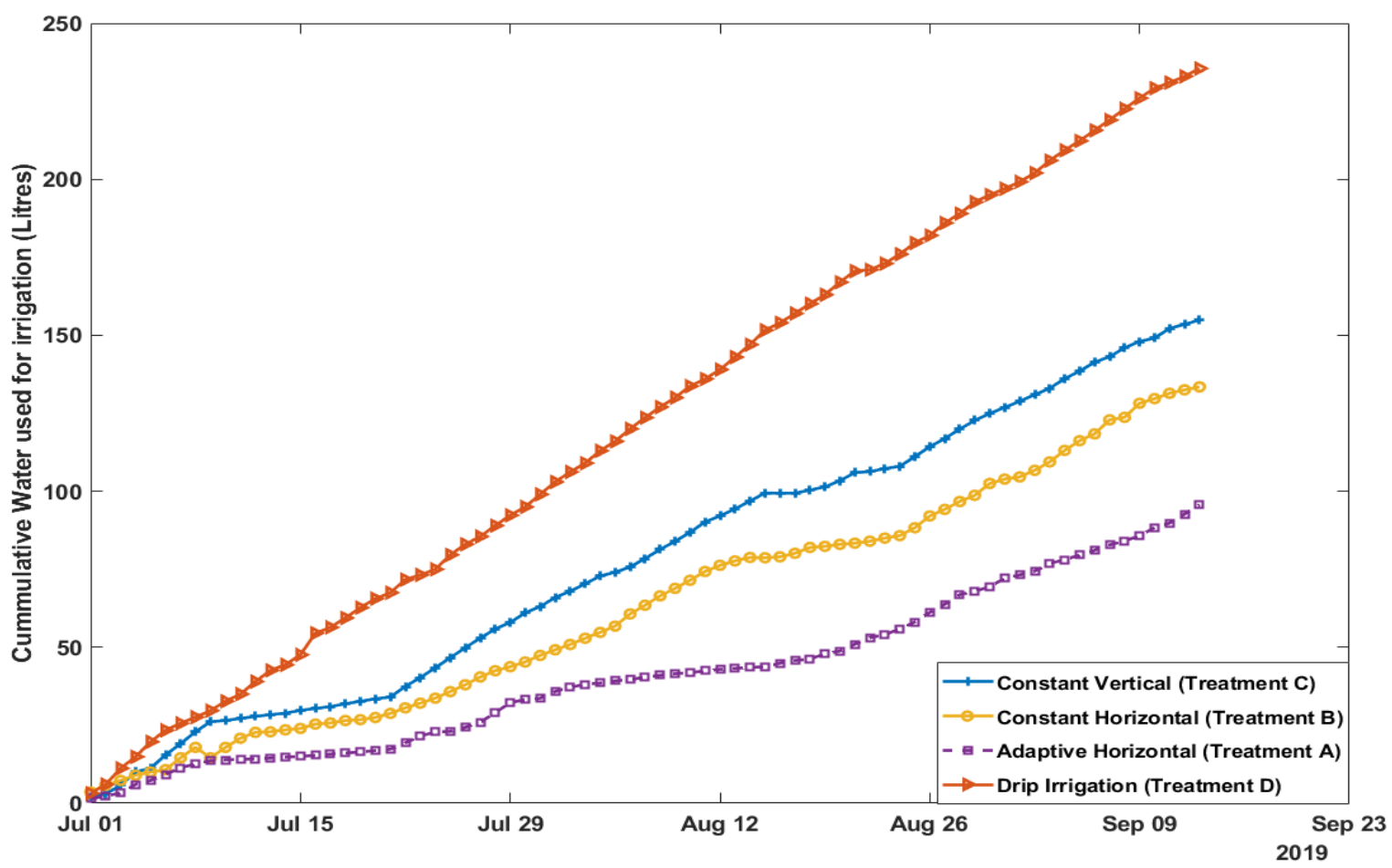

Figure 3. Graph of cumulative water consumption for the four treatments.

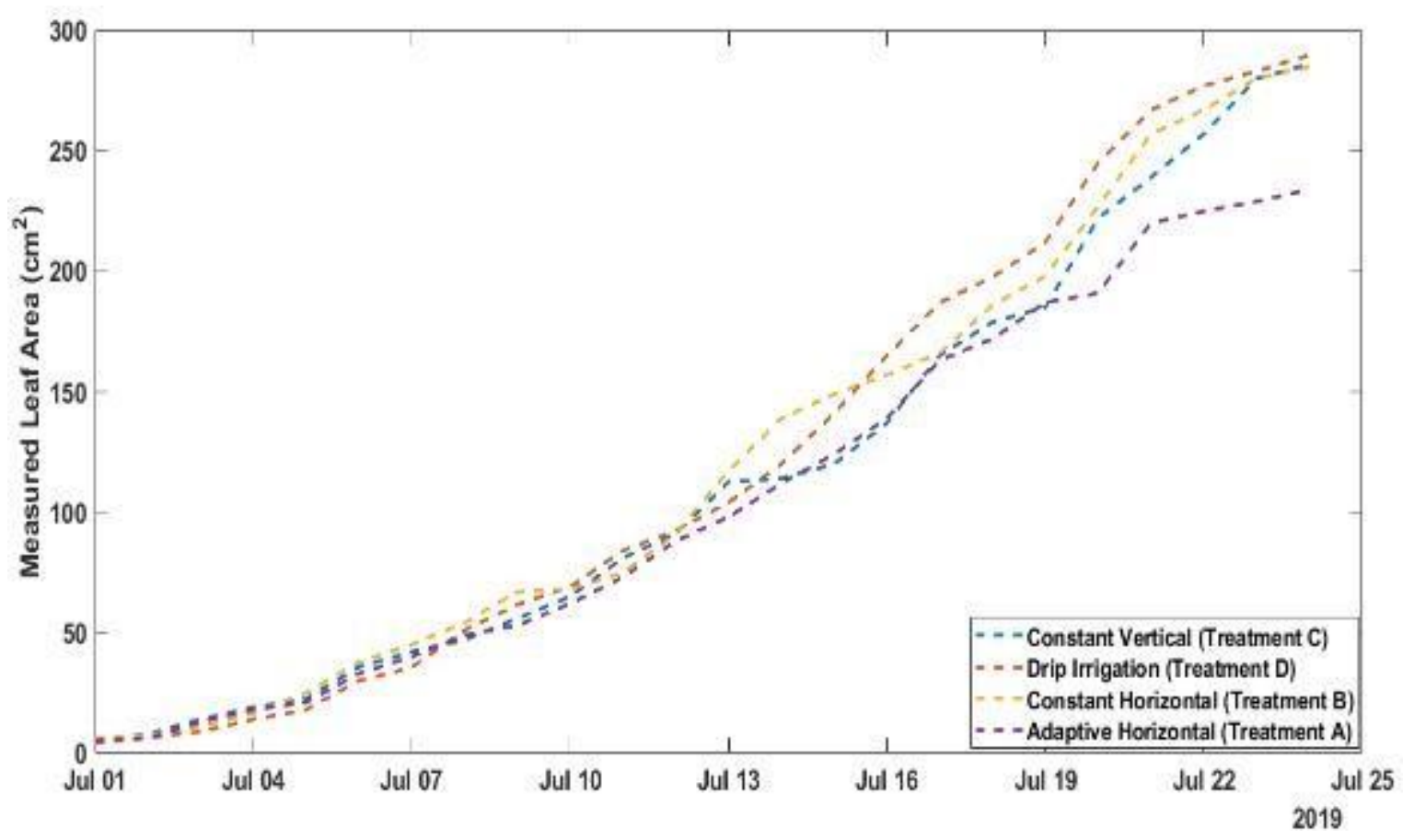

Figure 4. Graph of measured leaf area for the first three weeks after transplant for the four treatments. 


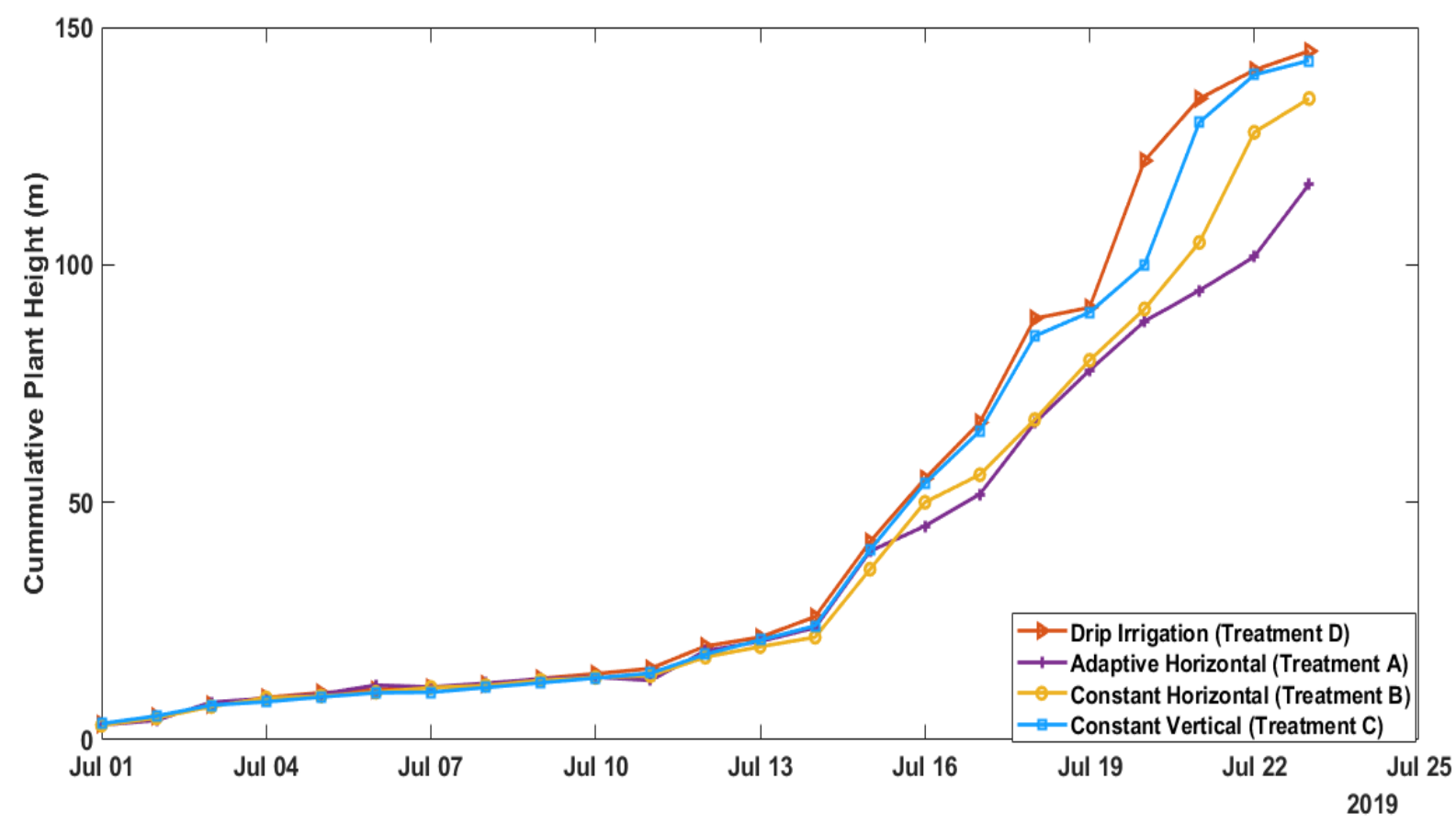

Figure 5. Graph of measured cumulative plant height for the first three weeks after transplanting for the four treatments.

Similarly, the measured plant height and leaf area of the two methods were compared with drip-irrigated cantaloupe plant having a high plant height and leave area on the average when compared with the fibrous capillary irrigated treatment as illustrated in Figure 4 and Figure 5. This is as a result of the fact that more water has been consumed by the drip irrigation system.

Table 1. Weight of harvested cantaloupe plants $(\mathrm{kg})$.

\begin{tabular}{ccccc}
\hline Sample & $\begin{array}{c}\text { Adaptive } \\
\text { Horizontal } \\
\text { (Treatment A) }\end{array}$ & $\begin{array}{c}\text { Constant } \\
\text { Horizontal } \\
\text { (Treatment B) }\end{array}$ & $\begin{array}{c}\text { Constant } \\
\text { Vertical } \\
\text { (Treatment C) }\end{array}$ & $\begin{array}{c}\text { Drip Irrigation } \\
\text { (Treatment D) }\end{array}$ \\
\hline $\mathbf{1}$ & 0.890 & 1.250 & 1.235 & 1.76 \\
$\mathbf{2}$ & 0.945 & 1.195 & 1.475 & 1.56 \\
Total & 0.9175 & 1.2225 & 1.355 & 1.66 \\
(Average) & & & & \\
\hline
\end{tabular}


Table 2. The sweetness of harvested cantaloupe plants (Brix).

\begin{tabular}{ccccc}
\hline Sample & $\begin{array}{c}\text { Adaptive } \\
\text { Horizontal } \\
\text { (Treatment A) }\end{array}$ & $\begin{array}{c}\text { Constant } \\
\text { Horizontal } \\
\text { (Treatment B) }\end{array}$ & $\begin{array}{c}\text { Constant } \\
\text { Vertical } \\
\text { (Treatment C) }\end{array}$ & $\begin{array}{c}\text { Drip Irrigation } \\
\text { (Treatment D) }\end{array}$ \\
\hline $\mathbf{1}$ & 13.5 & 11.1 & 11.9 & 8.2 \\
$\mathbf{2}$ & 12.85 & 10.2 & 13.1 & 7.9 \\
Total & 13.175 & 12.5 & 10.65 & 8.05 \\
(Average) & & & & \\
\hline
\end{tabular}

Table 3. Water productivity index of Cantaloupe plants cultivation $\mathrm{kg} / \mathrm{m}^{3}$.

\begin{tabular}{ccccc}
\hline Sample & $\begin{array}{c}\text { Adaptive } \\
\text { Horizontal } \\
\text { (Treatment A) }\end{array}$ & $\begin{array}{c}\text { Constant } \\
\text { Horizontal } \\
\text { (Treatment B) }\end{array}$ & $\begin{array}{c}\text { Constant } \\
\text { Vertical } \\
\text { (Treatment C) }\end{array}$ & $\begin{array}{c}\text { Drip Irrigation } \\
\text { (Treatment D) }\end{array}$ \\
\hline $\mathbf{1}$ & 18.5 & 18.79 & 15.9 & 4.85 \\
$\mathbf{2}$ & 19.7 & 17.96 & 19 & 4.85 \\
Total & 19.1 & 18.375 & 17.45 & 4.85 \\
(Average) & & & & \\
\hline
\end{tabular}

Similarly, Tables 1, 2 and 3 present the results of the weight of fruit, sweetness and water use efficiency on the harvested cantaloupe plant. According to Table 1, the dripirrigated cantaloupe plant has a higher weight when compared to fibrous capillary irrigation treatments. While from Tables 2 and 3, the IoT based adaptive controlled fibrous capillary irrigation has water productivity index (WPI) of $19 \mathrm{~kg} / \mathrm{m}^{3}$ with average fruit sweetness of 13.5 Brix, while drip irrigation has WPI of $4.85 \mathrm{~kg} / \mathrm{m}^{3}$ and average sweetness of 8.05 degrees Brix $(\mathrm{oBx})$ on the harvested fruit during cultivation of cantaloupe plants experiment. Therefore, the fibrous capillary irrigated cantaloupe plant to have better fruit quality in terms of sweetness and improved water use efficiency. This could be due to gradual water supply to the root zone of the plant through the fibrous capillary interface, based on its demand which has an effect on the sugar content of the fruit. Also, the subsurface nature of water supply to the root zone of the plant in fibrous capillary irrigation, reduce the rate of water loss due to evaporation from the soil. This could also be responsible for higher water efficiency in fibrous capillary irrigation. Tables 1, 2 and 3 was used to further analyse the statistical performance of the four treatments using Analysis of Variance (ANOVA) significant difference was established among the four treatments. 
Table 4. ANOVA Table result from Table 1.

\begin{tabular}{cccccc}
\hline \multicolumn{5}{c}{ Weight of harvested Cantaloupe plant $(\mathbf{k g})$} \\
\hline Source & $\begin{array}{l}\text { Degree } \\
\text { freedom (df) }\end{array}$ & $\begin{array}{l}\text { Sum } \\
\text { Square (ss) }\end{array}$ & $\begin{array}{c}\text { Mean } \\
\text { Square(ms) }\end{array}$ & F-Statistics \\
\hline Treatment & 3 & 0.568 & 0.189 & 14.538 \\
Error & 4 & 0.053 & 0.013 & \\
Total & 7 & 0.621 & & \\
\hline
\end{tabular}

Table 5. ANOVA Table result from Table 2.

\begin{tabular}{cccccc}
\hline \multicolumn{6}{c}{ The sweetness of harvested Cantaloupe plant (Brix) } \\
\hline Source & $\begin{array}{l}\text { Degree } \\
\text { freedom }(\mathbf{d f})\end{array}$ & $\begin{array}{l}\text { of } \\
\text { (ss) }\end{array}$ & of Square & $\begin{array}{c}\text { Mean } \\
\text { Square(ms) }\end{array}$ & F-Statistics \\
& & & & & \\
\hline Treatment & 3 & 31.54 & 10.51 & 11.587 \\
Error & 4 & 3.63 & 0.907 & \\
Total & 7 & 35.17 & & \\
& & & & & \\
\hline
\end{tabular}

Table 6. ANOVA Table result from Table 3.

\begin{tabular}{|c|c|c|c|c|}
\hline \multicolumn{5}{|c|}{ Water Productivity Index (WPI) of Cantaloupe plant cultivation $\left(\mathrm{kg} / \mathrm{m}^{\mathbf{3}}\right)$} \\
\hline Source & $\begin{array}{l}\text { Degree of } \\
\text { freedom }(\mathrm{df})\end{array}$ & $\begin{array}{l}\text { Sum of Square } \\
\text { (ss) }\end{array}$ & $\begin{array}{c}\text { Mean Square } \\
(\mathrm{ms})\end{array}$ & F-Statistics \\
\hline Treatment & 3 & 271.0 & 91.5 & 107 \\
\hline Error & 4 & 3.41 & 0.85 & \\
\hline Total & 7 & 274.4 & & \\
\hline
\end{tabular}

In order to test for the significant differences between the four treatments, using $95 \%$ confidence level, i.e. $\propto=0.05$, in Table 4,5 and 6 , the $F$ value calculated is $14.538,11.587$ and 107 while the $F$ tabulated is 6.5914 . Since $F_{\propto}<F_{T}$, ie $14.538>6.5914,11.587>$ 6.5914 , and $107>6.5914$, therefore we reject the null hypothesis, meaning that there are significant differences between the means of the treatments A, B, C and D in term of the average weight, sweetness and water productivity index of harvested cantaloupe plant. Therefore, the result obtained from the ANOVA analysis shows that there is significant difference among the four treatments. 


\section{Conclusion}

An experimental investigation on the performance comparison of drip and fibrous capillary irrigation system on the cultivation of cantaloupe plant has been presented in this paper. Based on the results, the proposed irrigation methods with improved monitoring can enhance precision irrigation towards the realization of water-saving agriculture. From the performance comparison, both irrigation methods have their strength and weakness in cantaloupe plant cultivation. The result obtained from the ANOVA analysis shows that there is significant difference among the four treatments. For fibrous capillary irrigation method, the quality of fruit is found to be good with high sweetness level and higher water productivity index (WPI) compared to drip irrigation method. On the other hand, drip irrigation method produced heavier cantaloupe fruit. However, it has low water productivity index (WPI) compared to the fibrous capillary irrigation method. Therefore, it is expected that this research effort will guide farmers to adopt an effective irrigation method which complies with their cultivation objective whether to produce a good cantaloupe quality or heavier cantaloupe fruit.

Acknowledgement: The authors acknowledge the Universiti Teknologi Malaysia and the Ministry of Higher Education Malaysia (MOHE), for their partial financial support through their Prototype Research Grant Scheme (PRGS) Vote No. Q.J130000.2651.17J53.

Conflicts of Interest: The authors declare no conflict of interest in this paper.

\section{References}

Abioye, A. E., Zainal Abidin. M., Azimi Mahmud. M. S., et al. (2020). IoT-based monitoring and data-driven modelling of drip irrigation system for mustard leaf cultivation experiment. Information Processing in Agriculture, In Press, Corrected Proof. https://doi.org/10.1016/j.inpa.2020.05.004

Abioye, A. E., Zainal Abidin. M., Saiful, Azimi Mahmud, M. S., et al., (2020). A review on monitoring and advanced control strategies for precision irrigation. Computers and Electronics in Agriculture, 173, 105441. https://doi.org/https://doi.org/10.1016/j.compag.2020.105441

Asia Society, (2019). Asia's Next Challenge: Securing the Region's Water Future. Retrieved on February 4th, 2020, from https://asiasociety.org/asias-next-challenge-securing-regions-water-future-0

Awang, Y., Shaharom, A. S., Mohamad, R. B., et al. (2009). Chemical and physical characteristics of cocopeatbased media mixtures and their effects on the growth and development of celosia cristata. American Journal of Agricultural and Biological Science, 4(1), 63-71. https://doi.org/10.3844/AJAB.2009.63.71

Idham A. R. M. K., Zainal Abidin, M. S., Izran Ishak, M. H., et al. (2018). Analysis of Fibrous Interface Capillary Irrigation System Using HYDRUS 2D / 3D for High Water Saving Agriculture. In MSAE Conference, Serdang, Selangor, 1-8.

Li, Q., Sugihara, T., Kodaira, M., et al., (2018). Water Use Efficiency of Precision Irrigation System under Critical Water-saving Condition. In 14th International Conference on Precision Agriculture June, Montreal, Quebec, Canada, 1-7. 
Martínez, J., \& Reca, J. (2014). Water use efficiency of surface drip irrigation versus an alternative subsurface drip irrigation method. Journal of Irrigation and Drainage Engineering, 140(10). https://doi.org/10.1061/(ASCE)IR.1943-4774.0000745

Masde, R. M. M., \& Mohd, N. R. N. (2016). Overview of Melon Industry in Malaysia. Malaysian Agriculture Research and Development Institute, MARDI. https://doi.org/10.1097/NOR.0b013e3181db5459

Oborkhale, L., Abioye, A. E., Egonwa, et al., (2015). Design and Implementation of Automatic Irrigation Control System. IOSR Journal of Computer Engineering (IOSR-JCE), 17(4), 99-11. https://doi.org/10.9790/0661-174299111

Rahman, M. K. I. A., Abidin, M. S. Z., Azimi, M. S., Mahmud, S. B., Ishak, M. H. I., \& Emmanuel, A. A. (2019). Advancement of a smart fibrous capillary irrigation management system with an internet of things integration. Bulletin of Electrical Engineering and Informatics, 8(4), 1402-1410. https://doi.org/10.11591/EEI.V8I4.1606

Rhuanito, S. F., Bailey, D., Balkaran, S., \& Bernier, J. (2016). Improving cantaloupe fruit sugar content in the UVI Commercial Aquaponic System.

Saiful, M., Mahmud, A., Zainal Abidin, M. S, et al., (2020). Robotics and Automation in Agriculture: Present and Future Applications. Application of Modelling and Simulation, 4, 130-140. https://doi.org/http://arqiipubl.com/ojs/index.php/AMS_Journal/article/view/130

Semananda, N., Ward, J., \& Myers, B. (2018). A Semi-Systematic Review of Capillary Irrigation: The Benefits, Limitations, and Opportunities. Horticulturae, 4(3), 23. https://doi.org/10.3390/horticulturae4030023

Seyfi, K., \& Rashidi, A. M. (2007). Effect of Drip Irrigation and Plastic Mulch on Crop Yield and Yield Components of Cantaloupe. International Journal of Agriculture \& Biology, 8530(9), 9-2.

Wiangsamut, B., Koolpluksee, M., \& Makhonpas, C. (2017). Yield, Fruit Quality and Growth of 4 Cantaloupe Varieties Grown in Hydroponic System and Drip Irrigation Systems of Substrate and Soil Culture. International Journal of Agricultural Technology, 13(7), 1381-1394.

Yahya, A., Safie, H., \& Kahar, S. (1997). Properties of cocopeat-based growing media and their effects on two annual ornamentals. Journal of Tropical Agriculture and Food Science, 25(2), 151-157. Retrieved from http://rac1.mardi.gov.my/jtafs/25-2/Cocopeat-based.pdf

Zainal Abidin M. S., Shibusawa, S., Ohaba, M., et al., (2014). Capillary flow responses in a soil - plant system for modified subsurface precision irrigation. Precision Agriculture, 15, 17-30. https://doi.org/10.1007/s11119-013-9309-6 